\title{
A digital enzyme-linked immunosorbent assay for ultrasensitive measurement of amyloid- $\beta$ 1-42 peptide in human plasma with utility for studies of Alzheimer's disease therapeutics
}

\author{
Linan Song ${ }^{1}$ (D), D. Richard Lachno ${ }^{2 *}$, David Hanlon ${ }^{1 *}$, Adam Shepro $^{1}$, Andreas Jeromin ${ }^{1}$, Dipika Gemani',
} Jayne A. Talbot ${ }^{3}$, Margaret M. Racke ${ }^{3}$, Jeffrey L. Dage ${ }^{3}$ and Robert A. Dean ${ }^{3}$

\begin{abstract}
Background: Amyloid- $\beta$ 1-42 peptide $\left(A \beta_{1-42}\right)$ is associated with plaque formation in the brain of patients with Alzheimer's disease (AD). Pharmacodynamic studies of AD therapeutics that lower the concentrations of $A \beta_{1-42}$ in peripheral blood require highly sensitive assays for its measurement. A digital enzyme-linked immunosorbent assay (ELISA) using single molecule array (Simoa) technology has been developed that provides improved sensitivity compared with conventional ELISA methods using the same antibody reagents.

Methods: A sensitive digital ELISA for measurement of $A \beta_{1-42}$ using antibodies 3D6 and 21F12 was developed. Assay performance was evaluated by repeated testing of pooled human plasma and buffer diluent quality control samples to determine relative accuracy, intra- and inter-assay precision, limit of detection (LOD), lower limit of quantification (LLOQ), dilutional linearity, and spike recovery. The optimized assay was used to quantify $A \beta_{1-42}$ in clinical samples from patients treated with the $\beta$-site amyloid precursor protein cleaving enzyme 1 inhibitor LY2886721.

Results: The prototype assay measured $A \beta_{1-42}$ with an LOD of $0.3 \mathrm{pg} / \mathrm{ml}$ and an LLOQ of $2.8 \mathrm{pg} / \mathrm{ml}$ in plasma, calibrated using an $A \beta_{1-42}$ peptide standard from Fujirebio. Assay precision was acceptable with intra- and inter-assay coefficients of variation both being $\leq 10 \%$. Dilutional linearity was demonstrated in sample diluent and immunodepleted human plasma. Analyte spike recovery ranged from $51 \%$ to $93 \%$ with a mean of $80 \%$. This assay was able to quantify $A \beta_{1-42}$ in all of the 84 clinical samples tested. A rapid reduction in levels of $A \beta_{1-42}$ was detected within $1 \mathrm{~h}$ after drug treatment, and a dose-dependent decrease of $A \beta_{1-42}$ levels was also observed over the time course of sample collection.

Conclusions: This digital ELISA has potential utility in clinical applications for quantification of $A \beta_{1-42}$ in plasma where high sensitivity and precision are required.
\end{abstract}

Keywords: Digital ELISA, Ultrasensitive, $A \beta_{1-42}$, Plasma, Alzheimer's disease, Therapeutic

\footnotetext{
*Correspondence: drlachno@lilly.com; dhanlon@quanterix.com

Eli Lilly and Company, Windlesham, UK

'Quanterix Corporation, Lexington, MA, USA

Full list of author information is available at the end of the article
} 


\section{Background}

The major pathologic events associated with the development of Alzheimer's disease (AD) are aggregation of amyloid- $\beta(A \beta)$ peptides into plaques [1-5] and formation of neurofibrillary tangles from hyperphosphorylated tau protein in the brain $[2,5,6]$. Among the different neurotoxic $A \beta$ isoforms, amyloid- $\beta$ peptide $1-42\left(A \beta_{1-42}\right)$ is more prone to aggregation, hence constituting the predominant form in senile plaques [2, 7]. Measurement of $\mathrm{A} \beta_{1-42}$ levels in cerebrospinal fluid (CSF) has proved useful as an aid in early detection of AD, particularly when combined with other CSF AD biomarkers such as tau and phosphorylated tau proteins [8-15]. In contrast, plasma $\mathrm{A} \beta_{1-42}$ has been found to be of limited value as a diagnostic marker of $\mathrm{AD}$, with contradictory reports from a variety of studies and investigators [13-18], although a recent study [19] demonstrates that $A \beta_{1-42}$ is significantly decreased in subjects with AD. Nevertheless, plasma $A \beta_{1-42}$ continues to be of great interest as a pharmacodynamic marker of $\gamma$-secretase (GS) and $\beta$-site amyloid precursor protein cleaving enzyme 1 (BACE1) drug target engagement in studies of candidate therapeutics [20, 21]. For example, monitoring the pharmacodynamic changes in plasma $A \beta_{1-42}$ levels can aid in the dose optimization of GS or BACE1 [20-24]. Assays that are sensitive enough to allow accurate and precise quantification of low concentrations of $A \beta_{1-42}$ in plasma in clinical trials of candidate $\mathrm{A} \beta$-lowering therapeutics would benefit $\mathrm{AD}$ research efforts.

Currently, enzyme-linked immunosorbent assays (ELISA), including laboratory-developed tests and commercial kits that use different analytical platforms, have been specifically validated for measuring $A \beta_{1-42}$ in CSF and serum or plasma from circulating peripheral blood [25-35]. However, in subjects who receive investigational $A \beta$-lowering drugs, plasma $A \beta_{1-42}$ concentrations may decrease to levels precluding reliable quantification with currently available immunoassays. To effectively measure these very low $A \beta_{1-42}$ concentrations and more reliably assess GS and BACE1 target engagement as well as the pharmacodynamic response profile, analytical methods with very low limits of quantification are required.

In the present study, a digital ELISA was developed for measuring plasma $A \beta_{1-42}$ with improved sensitivity using single molecule array (Simoa) technology [36, 37] with antibodies 3D6 and 21F12, directed at the N- and C-termini of $A \beta_{1-42}$, respectively. Simoa is based on the isolation of individual immunocomplexes formed on paramagnetic particles using standard ELISA reagents. Beads are subsequently loaded and sealed into an array of femtoliter-sized wells for digital measurement of signals. This ability to trap and detect single protein molecules provides unprecedented sensitivity compared with standard ELISA assays, where signal measurement usually occurs within the reacting mixture in comparatively large volumes [38-41]. The goals of this study were also to develop a digital ELISA using the same monoclonal antibodies used in previous clinical trials sponsored by Eli Lilly and Company (Indianapolis, IN, USA), evaluate the analytical performance, and demonstrate its ability to quantify $A \beta_{1-42}$ in samples from subjects treated with a previously characterized $A \beta$-lowering agent using the fully automated Simoa HD-1 Analyzer (Quanterix, Lexington, MA, USA).

\section{Methods \\ Reagents}

Two monoclonal anti-A $\beta_{1-42}$ antibodies (3D6 and 21F12) were obtained from ADx NeuroSciences (Gent, Belgium). A concentrated stock of $A \beta_{1-42}$ peptide from the Quanterix commercial Simoa $A \beta_{1-42}$ Kit (catalogue number 100093) was used for calibration during assay development. Additionally, $\mathrm{A} \beta_{1-42}$ peptide standard from the INNOTEST $^{\otimes} \beta$-Amyloid ${ }_{(1-42)}$ assay (catalogue number 51625; Fujirebio, Gent, Belgium) was used as a reference calibrator for analysis of clinical samples.

\section{Preparation of Simoa reagents}

Capture beads were prepared by conjugating 3D6 (specific to the $\mathrm{N}$-terminus of $\left.\mathrm{A} \beta_{1-42}\right)$ following standard two-step 1-ethyl-3-(3-dimethylaminopropyl)carbodiimide (EDAC) coupling chemistry. Briefly, carboxylated paramagnetic particles (Agilent Technologies, Santa Clara, CA, USA) were first washed three times with PBS plus $1 \%$ Tween 20 and twice with $50 \mathrm{mM}$ 2-(N-morpholino)ethanesulfonic acid (MES), pH 6.2. The beads were activated with $0.5 \mathrm{mg} / \mathrm{ml}$ freshly prepared EDAC in cold $50 \mathrm{mM}$ MES buffer ( $\mathrm{pH}$ 6.2) for 30 minutes at room temperature. After activation and another immediate wash with cold MES buffer, the activated beads were conjugated with an optimized concentration (e.g., $0.5 \mathrm{mg} / \mathrm{ml}$ ) of antibody in MES buffer ( $\mathrm{pH}$ 6.2) for $2 \mathrm{~h}$ at room temperature. Following antibody coupling, the capture beads were washed twice with PBS plus 1\% Tween 20, followed by blocking with PBS plus $1 \%$ bovine serum albumin (BSA) for 30 minutes. After blocking, the capture beads were stored in $50 \mathrm{mM}$ Tris buffer with $1 \% \mathrm{BSA}, \mathrm{pH} \mathrm{7.8,} \mathrm{at} 4{ }^{\circ} \mathrm{C}$ until required. The detection antibody (21F12, specific to the C-terminus of $A \beta_{1-42}$ ) was exchanged into PBS using Amicon ${ }^{\odot}$ Ultra 0.5-ml centrifugal filter devices (EMD Millipore, Billerica, MA, USA) and then reacted with EZ-link NHS-PEG4-Biotin (Thermo Fisher Scientific, Rockford, IL, USA) at 40- and 60-fold molar ratios of biotin to antibody for 30 minutes at room temperature. After biotinylation, the antibody was purified to remove excess free biotin using Amicon ${ }^{\odot}$ Ultra 0.5-ml centrifugal filter devices and stored at $4{ }^{\circ} \mathrm{C}$ for future use. 
Digital ELISA development for detection of $A \beta_{1-42}$

Capture beads were prepared using three different concentrations $(0.3,0.5$, and $0.7 \mathrm{mg} / \mathrm{ml})$ of 3D6 antibody during the bead conjugation process to optimize the target capture efficiency while maintaining a high level of monomericity (>80\%). The detection antibody (21F12) was biotinylated at two different molar ratios, 40-fold and 60-fold, of biotin to antibody. Each of the three capture bead concentrations was then tested with both biotinylated detection antibody preparations (described above) individually using an abbreviated three-point calibration curve $\left(0,1\right.$, and $10 \mathrm{pg} / \mathrm{ml}$ of $\mathrm{A} \beta_{1-42}$ peptide added to calibration diluent). The assay performance was evaluated by comparing dose response, background level, and signal-to-background (S/B) ratios for all six conditions initially tested.

\section{Simoa assay (digital ELISA)}

The prepared capture beads and biotinylated detection antibody detailed above were used to develop a digital ELISA for $A \beta_{1-42}$ measurement using the Simoa technology on a fully automated HD-1 Analyzer as described elsewhere [36, 39-41]. During the first step, $100 \mu \mathrm{l}$ of calibrators or diluted samples were mixed with the capture beads $\left(3 \times 10^{6} / \mathrm{ml}\right)$ and biotinylated detection antibody $(0.1 \mu \mathrm{g} / \mathrm{ml})$ for 35 minutes at room temperature, then washed three times with wash buffer containing $5 \times$ PBS and $0.1 \%$ Tween 20. After washing, $A \beta_{1-42}$ captured on beads was enzymatically labeled by incubating it with 200 pM streptavidin- $\beta$-galactosidase for 5 minutes. Following a second wash, a solution of enzyme substrate, resorufin $\beta$-D-galactopyranoside, was added, and the capture beads were resuspended and then loaded into Simoa arrays, each containing 216,000 femtoliter-sized wells for detection. The assay was quantified by measurement of signals from bound analyte targets on the beads in units of average enzymes per bead (AEB) as previously described [36, 37, 41].

\section{Test sample preparation}

Immunodepleted human plasma (IHP) was provided by Eli Lilly and Company. Ethylenediaminetetraacetic acid (EDTA) plasma from individual healthy donors was purchased from BioreclamationIVT (Hicksville, NY, USA). To enable precision studies, a pool of normal human EDTA plasma was prepared in-house by combining five individual healthy donor samples. The normal pool was divided into 1-ml aliquots using microcentrifuge tubes (catalogue number C-3228-1; BioExpress, Kaysville, UT, USA) and stored frozen at $-80{ }^{\circ} \mathrm{C}$. Quality control (QC) pools, designated control 1 to control 3, were also prepared by spiking $A \beta_{1-42}$ peptide into calibration diluent at three different levels $(20,5$, and $0.7 \mathrm{pg} / \mathrm{ml})$. After preparation, QC pools were divided into $0.5-\mathrm{ml}$ single- use aliquots using the microcentrifuge tubes (as above) and stored at $-80{ }^{\circ} \mathrm{C}$.

\section{Limit of detection and limit of quantification}

To estimate the limit of detection (LOD) using optimized reagents, eight-point calibration curves were freshly prepared from a stock of $\mathrm{A} \beta_{1-42}$ peptide by serial dilution into calibration diluent at seven levels plus a blank (calibration diluent). Calibration curves were tested over ten runs, with each calibrator run in triplicate. The mean of $\mathrm{AEB}, \mathrm{SD}$, and coefficient of variation percentage (CV\%) were calculated for each calibrator, respectively. The lower limit of quantification (LLOQ) was determined by repeated testing of the spiked IHP samples at three different levels approaching the estimated LOD of the assay.

The LLOQ for the Quanterix $A \beta_{42}$ commercial assay was determined using the eight-point kit calibration curve. Each calibrator was tested in duplicate wells in two separate assay runs. The mean of AEB, SD, and CV\% was calculated for each calibrator. The calibrator AEB values were also interpolated against the fitted four-parameter logistic (4PL) curve, and mean concentration, SD, and CV\% were calculated. The LLOQ was determined by multiplying the lowest standard concentration with an interpolated CV $\leq 20 \%$ (and above the LOD of the assay) with the minimum required dilution $(4 \times)$ of a sample.

\section{Intra- and inter-assay precision}

Intra- and inter-assay precision were determined by testing three aliquots of the pooled normal human EDTA plasma (six replicates per aliquot) and two aliquots from controls 1-3 (in duplicate), repeated on 3 separate days. Within-run CV was calculated for the pooled plasma $(n=18)$ and with each of the three QC samples $(n=4)$ having expected values of $20 \mathrm{pg} / \mathrm{ml}$ (QC1), $5 \mathrm{pg} / \mathrm{ml}$ (QC2) and $0.7 \mathrm{pg} / \mathrm{ml}$ (QC3), respectively. Inter-assay precision was determined by averaging the results from different days $(n=3)$ and calculating the CV\% for each sample.

\section{Dilutional linearity}

Two plasma pools were investigated for dilutional linearity: one prepared from combined specimens from subjects treated with the BACE1 inhibitor LY2811376 and the other from a spiked normal human EDTA plasma pool prepared with addition of $60 \mathrm{pg} / \mathrm{ml}$ of $A \beta_{1-42}$. For each plasma pool, parallel twofold serial dilutions were performed using sample diluent and IHP until the LLOQ was reached, respectively. The dilution-corrected concentrations of $\mathrm{A} \beta_{1-42}$ were calculated from the interpolated concentrations at each dilution multiplied by the corresponding dilution factors. 


\section{Spike recovery}

Four individual normal plasma samples were spiked with two levels of $A \beta_{1-42}$ peptide, 5 and $20 \mathrm{pg} / \mathrm{ml}$, and then diluted four-fold using sample diluent. Nonspiked samples were tested in parallel and used to calculate spike recovery.

\section{Clinical sample sources}

Clinical samples from two phase I studies of the BACE1 inhibitor LY2886721 (Eli Lilly and Company) were used to evaluate the utility of the prototype digital ELISA in comparison with the commercial Simoa assay. In study I4O-MC-BACA, healthy volunteers received single oral doses in the range of $1-35 \mathrm{mg}$, or placebo, and in study I4O-MC-BACB, healthy volunteers received multiple oral doses of 5,15 , or $35 \mathrm{mg}$, or placebo, for 14 consecutive days. Samples selected from study I4O-MC-BACA were from subjects who received $7 \mathrm{mg}(n=3), 15 \mathrm{mg}$ $(n=3)$, or $35 \mathrm{mg}(n=3)$ of LY2886721 or placebo $(n=3)$, collected before dose administration and 1, 6, and $12 \mathrm{~h}$ after dosing. Samples selected from study I4O-MC-BACB were collected before dose administration on days 1 (pretreatment baseline), 4, 8, and 12 from subjects who received $5 \mathrm{mg}(n=3), 15 \mathrm{mg}(n=3)$, or $35 \mathrm{mg}(n=3)$ of LY2886721. Additionally, samples from part B of a phase I clinical trial (I3J-MC-LACE) of the BACE1 inhibitor LY2811376 (Eli Lilly and Company), where healthy volunteers received single oral doses of $30 \mathrm{mg}, 90 \mathrm{mg}$, or placebo [22], were combined to prepare low-concentration pools for assay precision testing.

All clinical studies were conducted in compliance with the revised (1996) Helsinki declaration of 1975, and all enrolled subjects provided informed consent for treatment and use of samples for research. The protocols permitted collection of plasma specimens before and during treatment for exploratory biomarker measurements. Blood specimens were collected into 6-ml plastic $\mathrm{K}_{2}$ EDTA-coated BD Vacutainer tubes (catalogue number 367863; BD Biosciences, San Jose, CA, USA). After separation, plasma was divided into $0.5-\mathrm{ml}$ aliquots and stored frozen at less than or equal to $-70{ }^{\circ} \mathrm{C}$ in $2-\mathrm{ml}$ screw-topped polypropylene vials (catalogue number 72.694.056; Sarstedt, Nümbrecht, Germany).

\section{Measurement of $A \beta_{1-42}$ in human plasma pools and clinical samples}

Plasma samples stored at $-80{ }^{\circ} \mathrm{C}$ were first thawed at room temperature, then mixed by brief vortexing and centrifuged at $20,000 \times g$ for 3 minutes to pellet any particulates. The supernatant was removed, then diluted four-fold with sample diluent and analyzed using a digital ELISA. Clinical samples were analyzed in batches by subject. Two 8-point calibration curves, one prepared using the $A \beta_{1-42}$ peptide from Quanterix and the other with material from Fujirebio, were included in each batch, in addition to one aliquot from two QC pools (QC1 and QC3) already described, to verify run validity. All calibrators, QC, and clinical samples were tested in duplicate, with a single result reported.

\section{Simoa comparison}

All clinical samples were analyzed in parallel using the Simoa $A \beta_{1-42}$ assay described above and the commercial Simoa kit from Quanterix that employs different antibody reagents for $A \beta_{1-42}$ capture (specific to the $\mathrm{N}$-terminus of $A \beta_{1-42}$ ) and detection (specific to the C-terminus of $\left.\mathrm{A} \beta_{1-42}\right)$. The $A \beta_{1-42}$ concentrations quantified from both assays were compared for all 84 samples tested. Additionally, on the basis of the results of clinical sample analysis, theoretical projections were made of each assay's ability to quantify decreasing concentrations of $\mathrm{A} \beta_{1-42}$ resulting from treatment with $\mathrm{A} \beta$-lowering therapeutics.

\section{$A \beta_{1-42}$ calibration standard comparison}

As a result of an observed difference in response of the calibrators, $A \beta_{1-42}$ peptides from the Quanterix commercial Simoa $A \beta_{1-42}$ Kit (catalogue number 100093) and the INNOTEST $^{\oplus} \beta$-Amyloid An-42) $_{(1)}$ assay from Fujirebio (catalogue number 51625) were compared independently of the Simoa assay. Because of carrier proteins present in the standards, it was not possible to use amino acid analysis (AAA) to directly confirm concentrations. Therefore, each standard was run in an acid urea gel [42] under totally denatured conditions and compared with an Eli Lilly reference standard prepared in formic acid and subjected to AAA. Briefly, the Lilly reference standard was diluted in formic acid to prepare a standard curve, and amounts of $1,0.5,0.25,0.125$, and $0.0625 \mathrm{ng}$ were loaded into wells on the acid urea gel. Additionally, the Quanterix standard, the INNOTEST ${ }^{\oplus}$ standard, and another Lilly substock of corporate reference standard were each diluted to achieve $0.25 \mathrm{ng} /$ well on the basis of their stated concentrations. Three sets of duplicates were made to run on two gels, thereby achieving individually diluted standard samples as triplicates (duplicates for the Eli Lilly substock because of space limitations on the gel). A Western blot using 3D6 antibody detection was employed to detect $A \beta_{1-42}$ peptide bands. A quadratic equation of the AAA standard curve was used to calculate the actual value for each of the Quanterix, INNOTEST ${ }^{\oplus}$, and Lilly substock standard samples.

\section{Data analysis}

A 4PL fit was used to calibrate the Quanterix commercial $A \beta_{1-42}$ kit assay according to the package insert, whereas a cubic calibration fit was used to quantify $A \beta_{1-42}$ with the prototype assay reported herein. For the prototype $A \beta_{1-42}$ assay, a cubic calibration regression 
Table 1 Prototype assay calibration performance summary using Quanterix standard for assay evaluation and clinical test batches

\begin{tabular}{|c|c|c|c|c|c|c|c|c|}
\hline \multirow[b]{2}{*}{ Theoretical concentration } & \multicolumn{8}{|c|}{ Concentration $^{\mathrm{a}}(\mathrm{pg} / \mathrm{ml})$} \\
\hline & 0.023 & 0.069 & 0.206 & 0.617 & 1.85 & 5.6 & 16.7 & 50.0 \\
\hline Run 1 & & 0.096 & 0.199 & 0.616 & 1.85 & 5.56 & 16.9 & 49.9 \\
\hline Run 2 & -0.011 & 0.066 & 0.224 & 0.614 & 1.77 & 5.67 & 17.2 & 49.7 \\
\hline Run 3 & -0.032 & 0.135 & 0.281 & 0.613 & 1.78 & 5.56 & 17.4 & 49.5 \\
\hline Run 4 & -0.012 & 0.080 & 0.201 & 0.615 & 1.87 & 5.48 & 16.9 & 49.9 \\
\hline Run 5 & -0.074 & 0.103 & 0.218 & 0.602 & 1.85 & 5.54 & 16.9 & 49.9 \\
\hline Run 6 & 0.061 & 0.088 & 0.194 & 0.620 & 1.85 & 5.48 & 17.0 & 49.8 \\
\hline Run 7 & & 0.066 & 0.202 & 0.627 & 1.82 & 5.56 & 16.8 & 49.9 \\
\hline Run 8 & & 0.234 & 0.323 & 0.525 & 2.11 & 5.23 & 17.5 & 49.8 \\
\hline Run 9 & & 0.214 & 0.240 & 0.583 & 1.82 & 5.43 & 17.8 & 49.2 \\
\hline N (total number of runs) & 5 & 9 & 9 & 9 & 9 & 9 & 9 & 9 \\
\hline Inter-assay mean & -0.014 & 0.120 & 0.231 & 0.602 & 1.86 & 5.5 & 17.2 & 49.7 \\
\hline SD & 0.049 & 0.063 & 0.044 & 0.031 & 0.099 & 0.121 & 0.350 & 0.237 \\
\hline CV\% & -362 & 52.1 & 19.0 & 5.2 & 5.3 & 2.2 & 2.0 & 0.5 \\
\hline Inter-assay RE, \% & -159 & 74.2 & 12.4 & -2.5 & 0.4 & -1.8 & 2.7 & -0.5 \\
\hline
\end{tabular}

CV\% Coefficient of variation percentage, RE Relative error

In runs 6-8, calibration curves prepared using both Quanterix and Fujirebio standards were included

${ }^{a}$ Concentrations were interpolated using the calibrator average enzymes per bead values against the fitted cubic curves

model provided better fitting accuracy than a 4PL, particularly for the upper end of the calibration range. Mean AEB, SD, and CV\% were calculated for all measured $\mathrm{A} \beta_{1-42}$ concentrations.

\section{Results}

\section{Assay calibration}

A summary of the calibrator performance in each of the prototype assay runs is presented in Table 1 . All runs included Quanterix calibrators. Calibration performance with the Quanterix standard was acceptable over the range of $0.206-50 \mathrm{pg} / \mathrm{ml}$ with back-calculated relative error between $-2.5 \%$ and $+12.4 \%$. Inter-assay $\mathrm{CV}$ varied from $0.5 \%$ to $19 \%$ over the same calibration range. The measurement range of the assay in plasma using the Quanterix standard, based on a four-fold dilution, was $0.824-200 \mathrm{pg} / \mathrm{ml}$.

Runs 6-8 included a calibration series prepared with standard peptide from an INNOTEST ${ }^{\circ}$ commercial assay kit. These results are presented in Table 2. An acceptable performance with the INNOTEST ${ }^{\circ}$ calibrator was obtained over the range of $0.617-50 \mathrm{pg} / \mathrm{ml}$, which translates to $2.47-200 \mathrm{pg} / \mathrm{ml}$ of plasma when a four-fold dilution is applied. Summaries of AEB for each of the calibration curves from the prototype assay runs are presented in Tables 3 and 4 for both calibrators.

Table 2 Prototype assay calibration performance summary using Fujirebio standard for assay evaluation and clinical test batches

\begin{tabular}{|c|c|c|c|c|c|c|c|c|}
\hline \multirow[b]{2}{*}{ Theoretical concentration } & \multicolumn{8}{|c|}{ Concentration $^{\mathrm{a}}(\mathrm{pg} / \mathrm{ml})$} \\
\hline & 0.023 & 0.069 & 0.206 & 0.617 & 1.85 & 5.6 & 16.7 & 50.0 \\
\hline Run 6 & -0.006 & 0.097 & 0.262 & 0.584 & 1.83 & 5.65 & 16.6 & 50.1 \\
\hline Run 7 & & 0.112 & 0.365 & 0.514 & 1.94 & 5.36 & 17.1 & 49.8 \\
\hline Run 8 & & 0.260 & 0.283 & 0.388 & 1.98 & 5.79 & 16.0 & 50.5 \\
\hline N (total number of runs) & 1 & 3 & 3 & 3 & 3 & 3 & 3 & 3 \\
\hline Inter-assay mean & -0.006 & 0.156 & 0.303 & 0.495 & 1.92 & 5.6 & 16.6 & 50.1 \\
\hline SD & & 0.090 & 0.054 & 0.100 & 0.077 & 0.220 & 0.508 & 0.365 \\
\hline CV\% & & 57.9 & 17.9 & 20.1 & 4.0 & 3.9 & 3.1 & 0.7 \\
\hline Inter-assay RE, \% & -125 & 128 & 47.5 & -19.8 & 3.6 & 0.8 & -0.7 & 0.3 \\
\hline
\end{tabular}

CV\% Coefficient of variation percentage, $R E$ Relative error

In runs 6-8, calibration curves prepared using both Quanterix and Fujirebio standards were included

${ }^{a}$ Concentrations were interpolated using the calibrator average enzymes per bead values against the fitted cubic curves 
Table 3 Summary of average enzymes per bead for prototype assay calibration using Quanterix standard for assay evaluation and clinical test batches

\begin{tabular}{|c|c|c|c|c|c|c|c|c|}
\hline & AEB & & & & & & & \\
\hline Theoretical concentration, pg/ml & 0.023 & 0.069 & 0.206 & 0.617 & 1.85 & 5.6 & 16.7 & 50.0 \\
\hline Run 1 & 0.006 & 0.008 & 0.010 & 0.023 & 0.112 & 0.794 & 5.951 & 27.615 \\
\hline Run 2 & 0.005 & 0.006 & 0.008 & 0.018 & 0.086 & 0.692 & 5.214 & 23.725 \\
\hline Run 3 & 0.005 & 0.007 & 0.009 & 0.018 & 0.089 & 0.703 & 5.774 & 29.431 \\
\hline Run 4 & 0.006 & 0.006 & 0.008 & 0.020 & 0.102 & 0.720 & 5.665 & 28.302 \\
\hline Run 5 & 0.005 & 0.006 & 0.008 & 0.018 & 0.096 & 0.720 & 5.603 & 28.131 \\
\hline Run 6 & 0.006 & 0.007 & 0.009 & 0.019 & 0.089 & 0.624 & 5.082 & 27.607 \\
\hline Run 7 & 0.011 & 0.012 & 0.014 & 0.025 & 0.091 & 0.618 & 4.674 & 25.809 \\
\hline Run 8 & 0.007 & 0.009 & 0.011 & 0.015 & 0.107 & 0.580 & 5.454 & 24.691 \\
\hline Run 9 & 0.007 & 0.009 & 0.010 & 0.018 & 0.084 & 0.608 & 5.409 & 24.587 \\
\hline N (total number of runs) & 9 & 9 & 9 & 9 & 9 & 9 & 9 & 9 \\
\hline Inter-assay mean & 0.006 & 0.008 & 0.010 & 0.019 & 0.095 & 0.673 & 5.425 & 26.655 \\
\hline SD & 0.00 & 0.00 & 0.00 & 0.00 & 0.01 & 0.07 & 0.39 & 2.00 \\
\hline $\mathrm{CV} \%$ & 26.4 & 24.8 & 19.1 & 15.4 & 10.4 & 10.3 & 7.2 & 7.5 \\
\hline
\end{tabular}

AEB Average enzyme per bead, CV\% Coefficient of variation percentage

In runs 6-8, calibration curves prepared using both Quanterix and Fujirebio standards were included

For comparison, calibration curves were prepared using $A \beta_{1-42}$ peptide standards from Quanterix and Fujirebio to evaluate the sensitivity of this assay. Figure 1 shows the representative calibration curves determined using both $A \beta_{1-42}$ peptides. The signals from the Quanterix $A \beta_{1-42}$ peptide were approximately threefold higher than those from the Fujirebio $A \beta_{1-42}$ peptide.

\section{$A \beta_{1-42}$ calibration standard comparison}

A 3D6 Western blot of $A \beta_{1-42}$ standards is shown in Fig. 2, and the measured concentrations of the two commercial standards interpolated from the Lilly standard calibration curve are presented in Table 5 . The measured amount of $A \beta_{1-42}$ in the Lilly peptide standard was close to the target value of $0.25 \mathrm{ng}$, whereas the Quanterix and Fujirebio standards were considerably higher $(+47 \%)$ and lower $(-51 \%)$, respectively.

\section{Limit of detection and lower limit of quantification}

The LOD and LLOQ results are presented in Table 6 . LOD is defined as an interpolated $A \beta_{1-42}$ level derived from a measured signal equivalent to the assay background from the buffer blank plus 2.5 times the SD. The calculated LOD for the prototype assay using the Quanterix peptide standard from ten calibration curves ranged from 0.09 to $0.15 \mathrm{pg} / \mathrm{ml}$ with an average of $0.12 \mathrm{pg} / \mathrm{ml}$, using a cubic fit regression model. The LLOQ was determined by repeated testing of the spiked IHP samples. The mean concentrations of $A \beta_{1-42}$ quantified from these samples (based on a Quanterix $A \beta_{1-42}$

Table 4 Summary of average enzymes per bead for prototype assay calibration using Fujirebio standard for assay evaluation and clinical test batches

\begin{tabular}{|c|c|c|c|c|c|c|c|c|}
\hline & AEB & & & & & & & \\
\hline Theoretical concentration, $\mathrm{pg} / \mathrm{ml}$ & 0.023 & 0.069 & 0.206 & 0.617 & 1.85 & 5.6 & 16.7 & 50.0 \\
\hline Run 6 & 0.006 & 0.007 & 0.008 & 0.012 & 0.031 & 0.164 & 1.105 & 8.401 \\
\hline Run 7 & 0.011 & 0.012 & 0.014 & 0.015 & 0.036 & 0.142 & 1.083 & 8.115 \\
\hline Run 8 & 0.011 & 0.012 & 0.013 & 0.013 & 0.033 & 0.149 & 0.931 & 8.084 \\
\hline $\mathrm{N}$ (total number of runs) & 3 & 3 & 3 & 3 & 3 & 3 & 3 & 3 \\
\hline Inter-assay mean & 0.009 & 0.010 & 0.012 & 0.013 & 0.033 & 0.151 & 1.040 & 8.200 \\
\hline SD & 0.003 & 0.003 & 0.003 & 0.002 & 0.002 & 0.011 & 0.095 & 0.175 \\
\hline CV\% & 28.8 & 29.1 & 25.0 & 13.8 & 6.6 & 7.3 & 9.1 & 2.1 \\
\hline
\end{tabular}

$A E B$ Average enzyme per bead, CV\% Coefficient of variation percentage

In runs 6-8, calibration curves prepared using both Quanterix and Fujirebio standards were included 


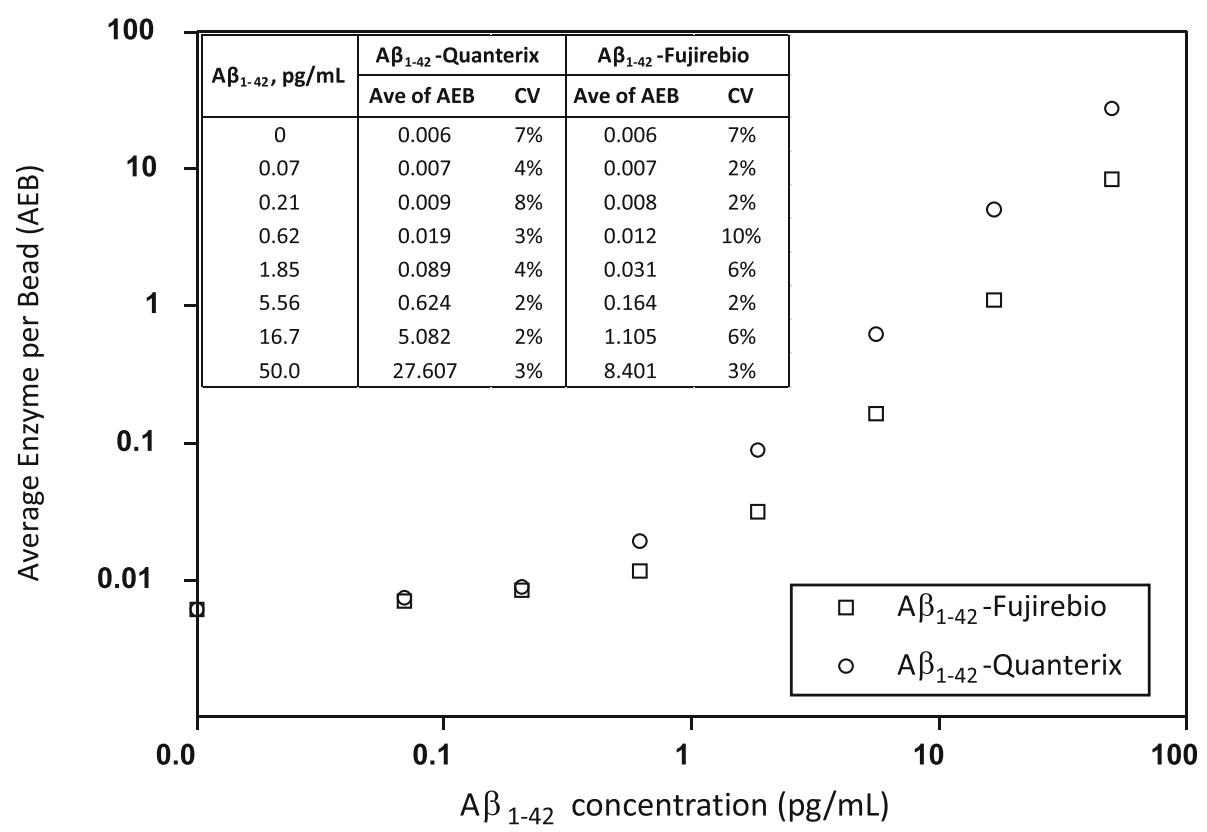

Fig. 1 Representative dose-response curves using the amyloid- $\beta$ 1-42 peptides (A $\left.\beta_{1-42}\right)$ from Quanterix and Fujirebio. For each calibration curve, average enzymes per bead (AEB) $(n=3)$ and coefficient of variation (CV of each calibration level are shown in the embedded table. The signals from the Quanterix $A \beta_{1-42}$ peptide were approximately threefold higher than those from the Fujirebio $A \beta_{1-42}$ peptide

peptide calibration curve) after four-fold dilution were $0.3,0.4$, and $0.6 \mathrm{pg} / \mathrm{ml}$ with $\mathrm{CV} \%$ of $8 \%, 7 \%$, and $7 \%$, respectively. Defining the LLOQ as the lowest $A \beta_{1-42}$ concentration that can be reliably quantified from plasma samples with a $\mathrm{CV} \% \leq 20 \%$ from repeated measurements, it was determined to be $1.2 \mathrm{pg} / \mathrm{ml}$ of plasma, after accounting for the four-fold preassay dilution.

When applied to the INNOTEST ${ }^{\circ} \mathrm{A} \beta_{1-42}$ peptide standard, the LOD calculated from three calibration curves was $0.31 \mathrm{pg} / \mathrm{ml}$, and the LLOQ determined

\section{Western blot of $A \beta_{1-42}$ standards}

\begin{tabular}{|c|c|c|c|c|c|c|c|c|c|c|c|c|}
\hline & & 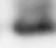 & 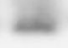 & $=$ & a & - & - & - & - & $=$ & - & - \\
\hline 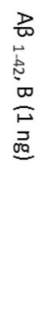 & 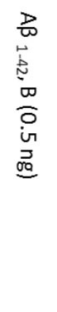 & 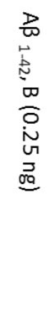 & 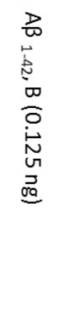 & 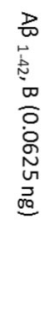 & 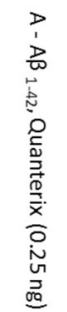 & 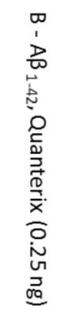 & 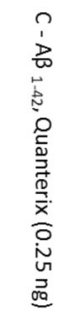 & 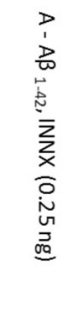 & 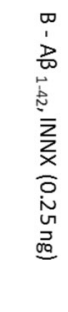 & 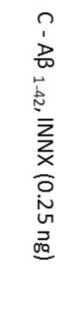 & 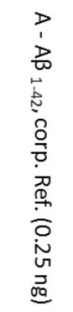 & 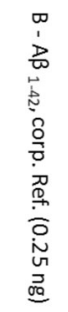 \\
\hline
\end{tabular}

Fig. 2 Western blot of amyloid- $\beta$ 1-42 peptide $\left(A \beta_{1-42}\right)$ peptide standards after 3D6 antibody detection following quantitative acid gel electrophoresis. Lanes 1-5 (left to right) $)_{1-42}$ reference standard from Lilly with amounts of $1,0.5,0.25,0.125$, and $0.0625 \mathrm{ng}$, respectively, loaded into each well. Lanes $6-$ 8 show three replicates of the diluted Quanterix $A \beta_{1-42}$ standard. Lanes 9-11 show three replicates of the diluted INNOTEST ${ }^{\otimes} A \beta_{1-42}$ standard. Lanes 12 and 13 show two replicates of another Lilly substock of $A \beta_{1-42}$ reference standard. From lane 6 to lane 13,0.25 ng of each $A \beta_{1-42}$ peptide was loaded per well, based upon their stated concentrations 
Table 5 Estimated amyloid- $\beta$ 1-42 peptide content of nominal 0.25-ng masses of calibration standard

\begin{tabular}{lcclr}
\hline $\begin{array}{l}\text { Calibration } \\
\text { standard }\end{array}$ & $\begin{array}{l}\text { Theoretical amount } \\
\text { loaded (ng) }\end{array}$ & $\begin{array}{c}\text { Mean amount } \\
\text { measured (ng) }\end{array}$ & $\begin{array}{l}\text { Relative } \\
\text { error (\%) }\end{array}$ & SEM \\
\hline Quanterix $^{\mathrm{a}}$ & 0.250 & 0.367 & +47 & 8.1 \\
Fujirebio $^{\mathrm{a}}$ & 0.250 & 0.123 & -51 & 7.3 \\
Lilly $^{\mathrm{b}}$ & 0.250 & 0.230 & -8 & 15.0 \\
\hline${ }^{\mathrm{a}} n=3$ & & & & \\
${ }_{\mathrm{b}}{ }_{n=2}$ & & & &
\end{tabular}

from measurement of spiked IHP was $2.8 \mathrm{pg} / \mathrm{ml}$ of plasma.

\section{Intra- and inter-assay precision}

The overall results from intra- and inter-assay precision are summarized in Table 7 . Intra-assay CV\% varied between $0.1 \%$ and $8 \%$, and inter-assay CV\% varied between $2 \%$ and $8 \%$.

\section{Dilutional linearity}

Figure 3 highlights the linearity of $A \beta_{1-42}$ measurement in a spiked pool from normal human EDTA plasma (Fig. 3a) and a pool prepared from drug-treated subjects (Fig. 3b) diluted with both sample diluent and IHP, respectively. Any dilutions that resulted in quantified $A \beta_{1-42}$ levels less than the LLOQ were excluded from analysis. For example, only three dilutions (two- to eightfold) are displayed for the pooled subjects treated with LY2811376, because starting concentrations in these drug-treated subjects were already very low. All corrected reportable values were within $20 \%$ of the nominal concentration obtained using a four-fold dilution. In addition, the $\mathrm{CV} \%$ of the replicate determinations at each dilution within the assay range were $\leq 20 \%$ for twoto eightfold dilutions. As shown in Fig. 3, dilutional linearity was observed for both types of pooled plasma samples with each diluent investigated. Linearity ranged from $91 \%$ to $115 \%$ when sample diluent was used (from 2 - to 128 -fold dilution) and $89 \%$ to $120 \%$ when using IHP as the diluent (from 2- to 64-fold dilution).

\section{Analyte spike recovery}

The recovery was calculated by subtracting the measured $A \beta_{1-42}$ concentration of the nonspiked sample from the measured concentration of the spiked sample

Table 6 Comparison of sensitivity using two different amyloid- $\beta$ 1-42 peptides as calibrators

\begin{tabular}{lcc}
\hline$A \beta_{1-42}$ peptide calibrator & $\mathrm{LOD}(\mathrm{pg} / \mathrm{ml})$ & $\mathrm{LLOQ}(\mathrm{pg} / \mathrm{ml})^{\mathrm{a}}$ \\
\hline Quanterix & 0.12 & 1.2 \\
Fujirebio & 0.31 & 2.8 \\
\hline
\end{tabular}

$A \beta$ amyloid- $\beta, L L O Q$ Lower limit of quantification, $L O D$ Limit of detection

${ }^{a} A \beta_{1-42}$ levels in neat plasma, accounting for four-fold preassay sample dilution
Table 7 Summaries of intra- and inter-assay precision for repeated testing of three quality control samples and one plasma pool

\begin{tabular}{|c|c|c|c|c|}
\hline \multirow[b]{2}{*}{ Sample } & \multicolumn{4}{|c|}{$\mathrm{A} \beta_{1-42}(\mathrm{pg} / \mathrm{ml})$} \\
\hline & $\overline{\mathrm{QC1}}$ & QC2 & QC3 & Plasma pool $^{\mathrm{a}}$ \\
\hline \multirow[t]{3}{*}{ Intra-assay means $(n=4)$} & 20.5 & 4.89 & 0.696 & 5.32 \\
\hline & 20.0 & 4.87 & 0.628 & 5.00 \\
\hline & 19.6 & 4.76 & 0.745 & 5.32 \\
\hline \multirow[t]{3}{*}{ Intra-assay CV\% } & 2 & 2 & 1 & 1 \\
\hline & 4 & 1 & 7 & 1 \\
\hline & 0.4 & 0.1 & 8 & 3 \\
\hline Inter-assay means $(n=3)$ & 20.0 & 4.84 & 0.689 & 5.20 \\
\hline Inter-assay CV\% & 2 & 2 & 8 & 4 \\
\hline
\end{tabular}

$A \beta$ amyloid- $\beta, C V \%$ Coefficient of variation percentage, QC Quality control ${ }^{a} n=18$ for plasma pool; the reported $A \beta_{1-42}$ levels in plasma pool were corrected for four-fold sample dilution

and dividing the result by the concentration spiked into each sample, reported as a percentage of the added spike. Recovery of spiked $A \beta_{1-42}$ from EDTA plasma was dependent on concentration and ranged from 51\% to $93 \%$, and it also varied between samples.

\section{Measurement of $A \beta_{1-42}$ in clinical samples}

The measured $A \beta_{1-42}$ concentrations in clinical specimens from subjects who received doses of LY2886721 are presented in Tables 8 and 9. For comparison, the $\mathrm{A} \beta_{1-42}$ concentrations in each sample were quantified using calibration curves generated with Quanterix and Fujirebio $A \beta_{1-42}$ standard peptides. For study I4O-MC$\mathrm{BACA}$, the change in $\mathrm{A} \beta_{1-42}$ concentration compared with the baseline (predose) value was calculated for each subsequent time point over the course of the study period (Fig. 4a). For study I4O-MC-BACB, predose treatment values were not available for two subjects from the 5-mg treatment group (subjects $\mathrm{R}$ and $\mathrm{S}$ ) and one subject from the 35-mg treatment group (subject Q); consequently, no change from baseline calculations were made. Instead, Fig. $4 \mathrm{~b}$ shows measured concentrations of $A \beta_{1-42}$ for each subject in study I4O-MC-BACB with increasing duration of treatment for each dose group. Measured concentrations and percentage changes shown in Fig. 4 were all determined using the Fujirebio $A \beta_{1-42}$ peptide standard. Regardless of the calibrator used, the percentage change in $A \beta_{1-42}$ concentration for the samples and calculated maximum measurable percentage changes were similar (Table 10). However, there were differences in the percentage reduction between the newly developed assay (79\%) and the Quanterix commercial kit assay (64\%), as listed in Table 10. Two QC samples (QC1 and QC3) measured during the clinical sample analysis were within the expected ranges (Table 11). 

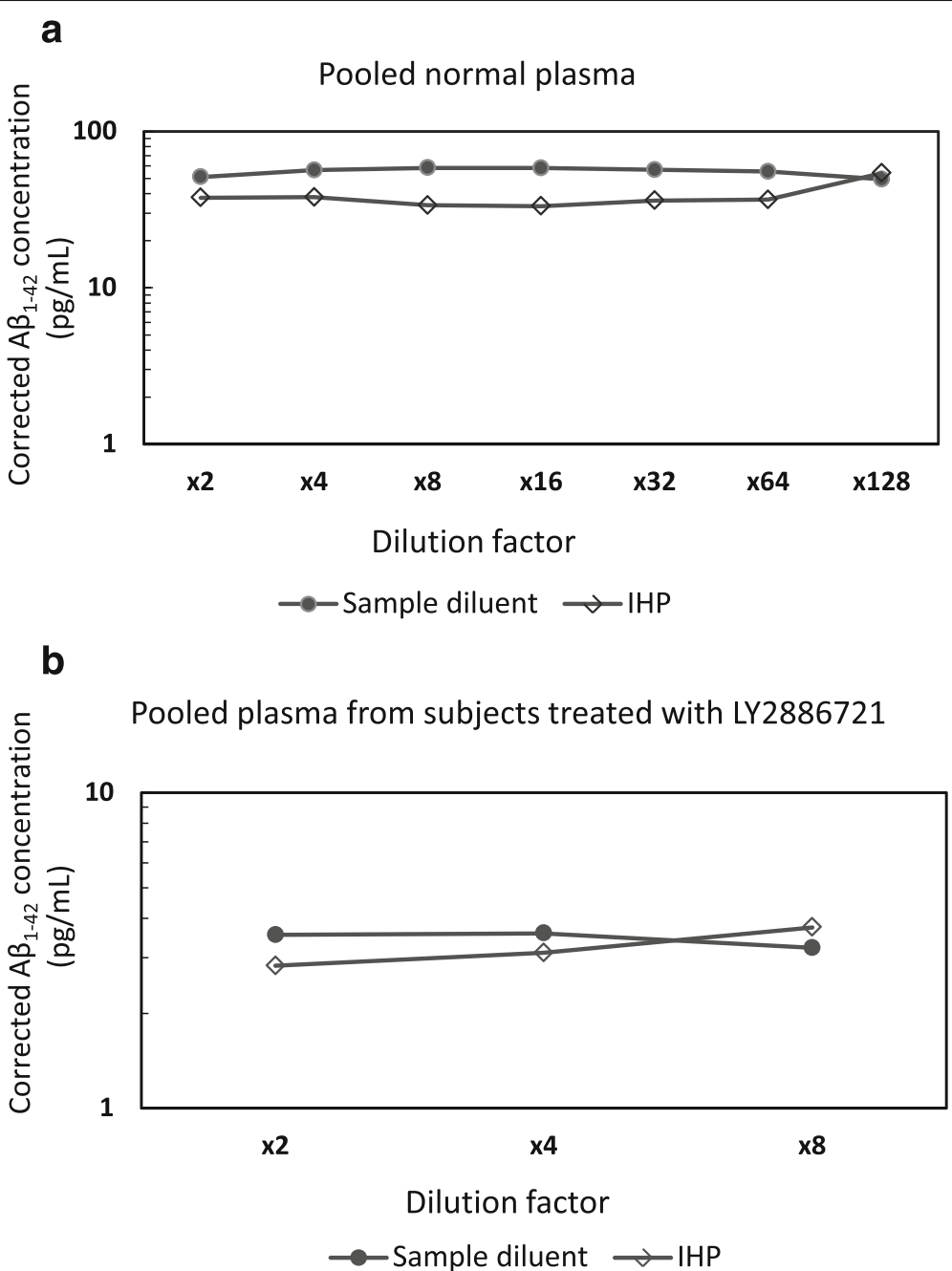

Fig. 3 The effect of sample dilution on quantification of amyloid- $\beta\left(A \beta_{1-42}\right)$ in plasma. Pooled ethylenediaminetetraacetic acid plasma spiked with $60 \mathrm{pg} / \mathrm{ml}$ of $A \beta_{1-42}$ peptide (a) and pooled samples from subjects treated with LY2886721 (b) were initially diluted twofold, followed by serial dilutions with sample diluent or immunodepleted human plasma (IHP). Dilutional linearity was observed using both types of diluent, ranging from $91 \%$ to $115 \%$ with sample diluent buffer (from 2- to 128-fold dilution) and from $89 \%$ to 120\% with IHP (from 2- to 64-fold dilution)

\section{Simoa assay comparison}

A comparison of clinical sample results between the new Simoa $A \beta_{1-42}$ assay reported here and the commercial Quanterix assay are presented in Fig. 5. Results from both assays correlated well $\left(r^{2}=0.85\right)$ (Fig. 5a and b). A total of 84 samples were tested using both assays, and each assay was calibrated using both available peptide sources. The correlations between results quantified using the different $A \beta_{1-42}$ peptide standards were very high within each assay, as shown in Fig. $5 c\left(r^{2}=0.997\right)$ and Fig. $5 d\left(r^{2}=0.977\right)$.

\section{Discussion}

Simoa technology uses an array of femtoliter-sized reaction chambers that is designed to capture and detect single peptides, resulting in a strong, rapidly developed fluorescent signal from a very small mass of analyte. The aim of this study was to develop and evaluate a Simoa assay for $A \beta_{1-42}$ with the same amyloid- $\beta$-specific antibodies (3D6 and 21F12) used as reagents in previous studies for measurements in human CSF and plasma following treatment with BACE inhibitors [24, 32, 35]. The analytical sensitivity of existing assays available was only just sufficient to quantify the extremely low plasma levels of $A \beta_{1-42}$ resulting from treatment [32], suggesting a need for improved assays to support development of more potent BACE inhibitors in the future. The performance characteristics of the prototype Simoa assay were evaluated, and the assay's capability for quantification of $A \beta_{1-42}$ at reduced levels in human plasma for pharmacodynamic evaluations related to the development of AD therapeutic targets was demonstrated. 
Table 8 Summary of measured amyloid- $\beta$ 1-42 peptide concentrations for samples from study 14O-MC-BACA ( $n=48)$ using both Quanterix and Fujirebio amyloid- $\beta$ 1-42 peptides for calibration

\begin{tabular}{|c|c|c|c|c|c|c|c|c|c|}
\hline \multirow[b]{3}{*}{ Subject } & \multirow[b]{3}{*}{ Dose } & \multicolumn{8}{|c|}{$A \beta_{1-42}(p g / m l)$} \\
\hline & & \multicolumn{4}{|c|}{ Quanterix $A \beta_{1-42}$ peptide calibration } & \multicolumn{4}{|c|}{ Fujirebio $A \beta_{1-42}$ peptide calibration } \\
\hline & & $\overline{\mathrm{Oh}}$ & $1 \mathrm{~h}$ & $6 \mathrm{~h}$ & $12 \mathrm{~h}$ & $\overline{\mathrm{Oh}}$ & $1 \mathrm{~h}$ & $6 \mathrm{~h}$ & $12 \mathrm{~h}$ \\
\hline $\bar{A}$ & Placebo & 16.8 & 16.9 & 17.0 & 18.1 & 39.7 & 39.9 & 40.0 & 42.9 \\
\hline $\mathrm{D}$ & Placebo & 14.7 & 13.3 & 10.9 & 12.0 & 34.4 & 31.1 & 25.1 & 27.8 \\
\hline G & Placebo & 18.6 & 18.8 & 18.3 & 20.8 & 43.9 & 44.6 & 43.3 & 49.4 \\
\hline B & $7 \mathrm{mg}$ & 18.7 & 12.2 & 8.03 & 8.25 & 44.3 & 28.3 & 17.9 & 18.5 \\
\hline C & $7 \mathrm{mg}$ & 21.0 & 19.6 & 7.64 & 6.70 & 49.9 & 46.4 & 17.0 & 14.6 \\
\hline$E$ & $7 \mathrm{mg}$ & 20.4 & 22.8 & 9.48 & 12.0 & 48.4 & 54.2 & 21.5 & 27.9 \\
\hline A & $15 \mathrm{mg}$ & 16.9 & 13.1 & 5.65 & 6.61 & 39.8 & 30.6 & 11.9 & 14.3 \\
\hline $\mathrm{F}$ & $15 \mathrm{mg}$ & 17.4 & 14.4 & 5.99 & 5.74 & 41.1 & 33.7 & 12.8 & 12.1 \\
\hline K & $15 \mathrm{mg}$ & 20.5 & 14.2 & 6.51 & 5.95 & 48.8 & 33.3 & 14.1 & 12.7 \\
\hline $\mathrm{H}$ & $35 \mathrm{mg}$ & 21.7 & 16.8 & 4.80 & 4.88 & 51.5 & 39.7 & 9.74 & 9.94 \\
\hline I & $35 \mathrm{mg}$ & 18.6 & 15.5 & 7.43 & 5.27 & 44.1 & 36.4 & 16.4 & 11.0 \\
\hline J & $35 \mathrm{mg}$ & 19.5 & 19.1 & 6.92 & 4.56 & 46.3 & 45.2 & 15.1 & 9.12 \\
\hline
\end{tabular}

$A \beta$ amyloid $-\beta$

To achieve better sensitivity using antibodies 3D6 and 21F12, Simoa reagents, assay buffers, and assay conditions were optimized. High-performance Simoa immunoassays, like conventional immunoassays, benefit from the same desirable characteristics, such as low background, high S/B ratio (robust dose-response slope), and a dynamic range suitable for the assay's intended use. Of the six conditions evaluated, capture beads coated with $0.5 \mathrm{mg} / \mathrm{ml} \mathrm{3D6}$ antibody and 21F12 antibody biotinylated at 40 -fold were determined to yield the most favorable assay performance with the best S/B ratio. Hence, these conditions were used to evaluate the Simoa $A \beta_{1-42}$ assay for analytical sensitivity and other assay performance characteristics.
For immunoassays, the choice of calibration regression models is essential to achieve accurate quantification for sample measurement. Although a $4 \mathrm{PL}$ fit is the most widely used regression model for immunoassays, a cubic fit was found to yield an overall better calibration accuracy for the prototype Simoa assay, with relative errors from back-fitted concentrations compared with the corresponding theoretical values typically $<5 \%$ for any calibrators greater than the LLOQ and a fit coefficient value $\left(r^{2}\right)>0.99$. Conversely, the relative errors were generally $>20 \%$ across the calibration range with $r^{2}<0.5$ using a 4PL regression model. Consequently, a cubic calibration fit was chosen for sample quantification using the prototype Simoa assay.

Table 9 Summary of measured amyloid- $\beta$ 1-42 peptide concentrations for samples from study 14O-MC-BACB ( $n=36)$ using both Quanterix and Fujirebio amyloid- $\beta$ 1-42 peptides for calibration

\begin{tabular}{|c|c|c|c|c|c|c|c|c|c|c|c|}
\hline \multirow[b]{3}{*}{ Subject } & \multirow[b]{3}{*}{ Dose } & \multicolumn{10}{|c|}{$A \beta_{1-42}(\mathrm{pg} / \mathrm{ml})$} \\
\hline & & \multicolumn{5}{|c|}{ Quanterix $A \beta_{1-42}$ peptide calibration } & \multicolumn{5}{|c|}{ Fujirebio $A \beta_{1-42}$ peptide calibration } \\
\hline & & Predose & Day 2 & Day 4 & Day 8 & Day 12 & Predose & Day 2 & Day 4 & Day 8 & Day 12 \\
\hline $\mathrm{R}$ & $5 \mathrm{mg}$ & & 11.9 & 14.5 & 13.2 & 12.2 & & 26.7 & 32.6 & 29.7 & 27.4 \\
\hline$S$ & $5 \mathrm{mg}$ & & 13.2 & 13.4 & 12.5 & 12.5 & & 29.7 & 30.2 & 28.1 & 28.0 \\
\hline $\mathrm{T}$ & $5 \mathrm{mg}$ & 23.6 & & 14.4 & 13.8 & 13.2 & 53.2 & & 32.5 & 31.2 & 29.8 \\
\hline $\mathrm{L}$ & $15 \mathrm{mg}$ & 19.0 & & 9.98 & 8.43 & 8.24 & 42.7 & & 22.4 & 18.9 & 18.4 \\
\hline M & $15 \mathrm{mg}$ & 16.9 & & 12.5 & 9.96 & 7.22 & 38.2 & & 28.2 & 22.3 & 16.1 \\
\hline$N$ & $15 \mathrm{mg}$ & 19.7 & & 13.7 & 10.5 & 9.52 & 44.4 & & 30.9 & 23.7 & 21.3 \\
\hline 0 & $35 \mathrm{mg}$ & 17.6 & & 3.33 & 4.35 & 1.65 & 39.5 & & 7.19 & 9.54 & 3.22 \\
\hline P & $35 \mathrm{mg}$ & 28.3 & & 6.58 & 4.33 & 7.70 & 63.5 & & 14.6 & 9.48 & 17.2 \\
\hline Q & $35 \mathrm{mg}$ & & 8.37 & 4.88 & 6.15 & 7.61 & & 18.7 & 10.8 & 13.7 & 17.0 \\
\hline
\end{tabular}




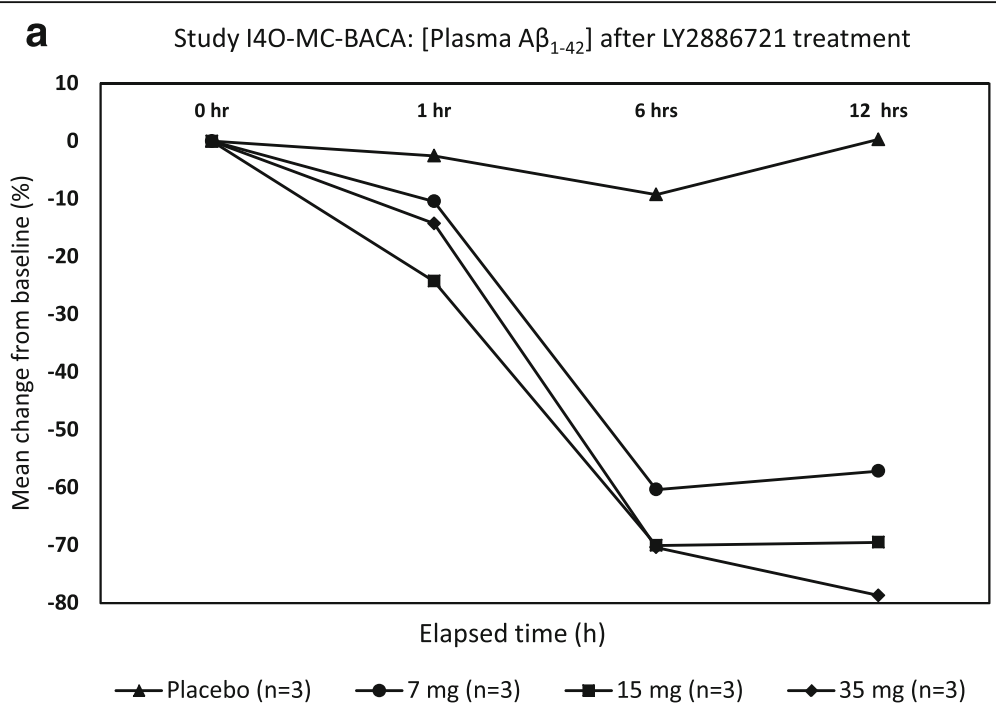

\section{b}

Study 14O-MC-BACB: [Plasma A $\beta_{1-42}$ ] after LY2886721 treatment

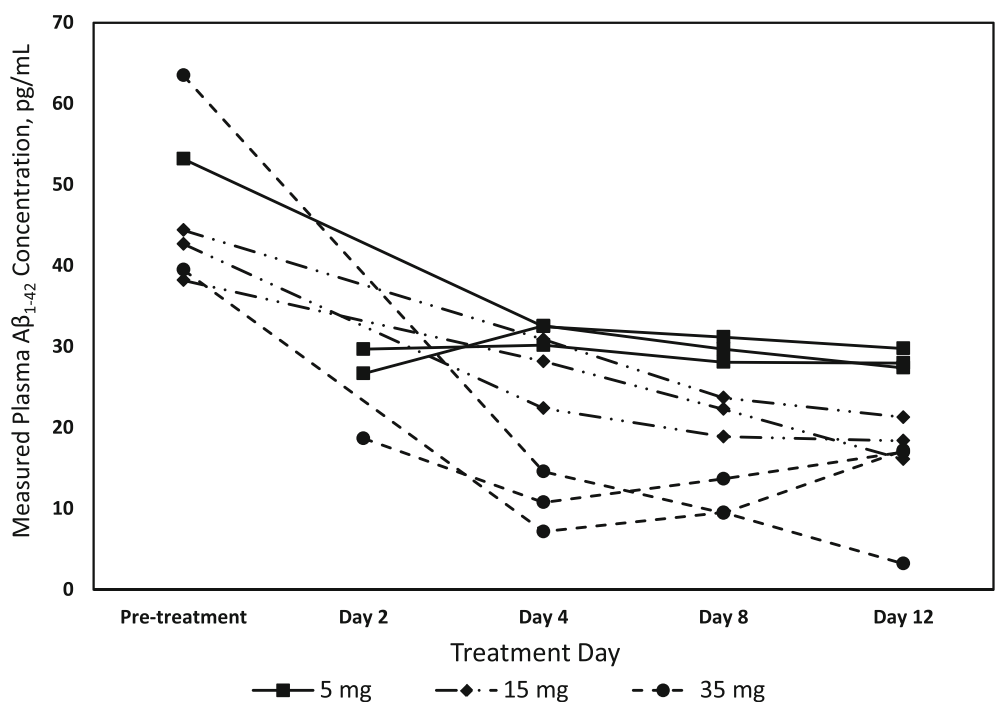

Fig. 4 Changes in plasma amyloid- $\beta$ 1-42 peptide $\left(A \beta_{1-42}\right)$ concentration in subjects who received oral doses of the $\beta$-site amyloid precursor protein cleaving enzyme 1inhibitor LY2886721 in separate clinical studies. a Mean percentage change in $A \beta_{1-42}$ concentration from baseline values for subjects treated with single doses of LY2886721 in study I4O-MC-BACA. b Plasma A $\beta_{1-42}$ concentration for individual subjects treated with 14 consecutive once-daily doses of LY2886721 in study 14O-MC-BACB. Samples from both studies were quantified with Fujirebio A $\beta_{1-42}$ peptide standard

In addition to low picogram-per-milliliter sensitivity, a major advantage of this Simoa assay is the linear $A \beta_{1-42}$ quantification observed when diluting plasma using sample diluent in standard tests or IHP in proportional linearity tests. Nonlinear assays restrict sample measurements to the calibrated range $[32,43]$. In contrast, this assay has shown robust dilutional linearity in the range of 2- to 128fold in measurements from a normal plasma pool spiked with $A \beta_{1-42}$ peptide. The dilutional linearity highlighted here allows samples that are well above the calibration range to be diluted into range without affecting the accuracy of measurement, thus expanding the application to clinical samples that have a much wider range of $A \beta_{1-42}$ levels. Additionally, sample dilution minimizes the matrix effects that are known to hinder accurate $A \beta_{1-42}$ measurement in plasma samples using ELISA [32, 33, 43, 44].

Reproducibility of the assay was evaluated using both pooled normal plasma and QC samples prepared in calibration diluent at three different levels spanning the assay calibrated range. Both intra- and inter-assay $\mathrm{CV} \%$ were $<10 \%$ at all concentrations tested over a period of 
Table 10 Comparison of prototype digital enzyme-linked immunosorbent assay (Simoa) amyloid- $\beta$ 1-42 peptide assay with the Quanterix commercial Simoa assay in the context of use as a pharmacodynamic marker in $\beta$-site amyloid precursor protein cleaving enzyme 1 inhibitor clinical trials

\begin{tabular}{|c|c|c|c|c|}
\hline ELISA & LLOQ (pg/ml; $\pm 20 \%)$ & Mean baseline $(\mathrm{pg} / \mathrm{ml})(\mathrm{SD})$ & $\begin{array}{l}\text { Maximum percentage } \\
\text { reduction (SD) }\end{array}$ & $\begin{array}{l}\text { Maximum quantifiable } \\
\text { percentage reduction }( \pm 20 \%)\end{array}$ \\
\hline \multicolumn{5}{|c|}{ Quanterix commercial $A \beta_{1-42}$ assay performance } \\
\hline \multicolumn{5}{|c|}{$A \beta_{1-42}$ peptide calibrator } \\
\hline Quanterix & $0.274(0.220-0.329)^{a}$ & $17.1(2.16)^{\mathrm{b}}$ & $64(5)^{c}$ & $98(96.5-98.7)$ \\
\hline Fujirebio & $0.824(0.659-0.989)^{a}$ & $39.6(4.93)^{b}$ & $64(5)^{c}$ & $98(95.4-98.3)$ \\
\hline \multicolumn{5}{|c|}{ Prototype Simoa $A \beta_{1-42}$ assay performance } \\
\hline \multicolumn{5}{|c|}{$A \beta_{1-42}$ peptide calibrator } \\
\hline Quanterix & $1.2(0.96-1.44)$ & $18.7(2.04)^{d}$ & $75(3)^{e}$ & $94(92.3-94.9)$ \\
\hline Fujirebio & $2.8(2.24-3.36)$ & $44.35(4.99)^{d}$ & $79(3)^{\mathrm{e}}$ & $94(92.4-94.9)$ \\
\hline
\end{tabular}

$A \beta$ amyloid- $\beta, E L I S A$ Enzyme-linked immunosorbent assay, LLOQ Lower limit of quantification

Note: Quanterix assay data show the maximum reduction of signal observed in I4O-MC-BACA and the assay's maximum quantifiable percentage reduction limit for the Quanterix commercial assay. Prototype Simoa assay data show results for the same parameters when using the newly developed Simoa assay

${ }^{a}$ LLOQ based on lowest standard with replicate performance $<20 \%$ coefficient of variation

${ }^{b}$ Baseline values are calculated from study 140-MC-BACA (not shown)

${ }^{c}$ Maximum percentage reduction calculated from 35-mg dose group of study 140-MC-BACA (not shown)

dMean baseline values are calculated from study I40-MC-BACA (Table 3)

'Maximum percentage reduction calculated from 35-mg dose group of study 140-MC-BACA (Table 5)

3 days, demonstrating high assay precision and reproducibility for $A \beta_{1-42}$ measurements.

The results of this study have also highlighted an unexpected major difference in the concentration value assignments of two $A \beta_{1-42}$ peptide standards used to calibrate the assays. The signal responses from the Quanterix $A \beta_{1-42}$ antigen were found to be significantly higher than those from the Fujirebio standard, although they both had the same assigned concentrations (Fig. 1). The reported $A \beta_{1-42}$ concentrations from the Fujirebio peptide calibration curve are approximately 2.4-fold higher across the range of samples tested (slope $=2.399$, $R^{2}=0.9973$; Fig. 5c) compared with the Quanterix calibration. For the predose samples, the Fujirebio-based $\mathrm{A} \beta_{1-42}$ concentrations are typically in the range of $35-60 \mathrm{pg} / \mathrm{ml}$, in line with previously reported results obtained using Fujirebio assays [33].

To gain a greater understanding of the differences between the two calibration standards used in the present methods study, the $A \beta_{1-42}$ peptide content was

Table 11 Summaries of plasma amyloid- $\beta$ 1-42 peptide assay measured from quality control samples (QC1 and QC3) during clinical sample analysis

\begin{tabular}{clllll}
\hline & \multicolumn{3}{l}{ Measured $A \beta_{1-42}(\mathrm{pg} / \mathrm{ml})$} & & \\
\cline { 2 - 4 } & Run 1 & Run 2 & Run 3 & Expected range of $A \beta_{1-42}(\mathrm{pg} / \mathrm{ml})^{\mathrm{a}}$ \\
\hline QC1 & 21.6 & 21.4 & 19.4 & $20 \pm 2$ \\
QC3 & 0.748 & 0.681 & 0.642 & $0.689 \pm 0.069$ \\
\hline
\end{tabular}

$A \beta$ amyloid- $\beta, Q C$ Quality control

a Expected range was within $\pm 10 \%$ of the averaged $A \beta_{1-42}$ concentration measured from precision study determined using a quantitative acid gel electrophoretic procedure that is run routinely at Lilly Research Laboratories (Indianapolis, IN, USA). Because of carrier proteins present in the standards, it was not possible to use AAA to directly confirm concentrations of each standard. Therefore, each standard was run on a totally denaturing gel system against an AAA-verified standard. The results showed that the Quanterix standard contained threefold more $A \beta_{1-42}$ peptide than the Fujirebio standard at the same assigned concentration. These disparate $A \beta_{1-}$ 42 peptide standard contents immediately explain the apparent difference in measured $A \beta_{1-42}$ concentrations in clinical samples, depending on the selected calibrator, as well as the difference in calibrator response observed during prototype assay development. Further investigation of the differences between these two standards, involving empirical chemical tests, may be warranted. Standardization of antigens for calibration has been a general challenge with different immunoassays in the absence of a universal reference standard. Recent progress toward availability of a globally recognized standard for $A \beta_{1-42}$ will facilitate comparisons of results from various assay platforms and improve clinical interpretation $[45,46]$.

To demonstrate the potential clinical utility of this assay for sensitive and reliable quantification of $A \beta_{1-42}$, a total of 84 plasma samples from subjects treated with the BACE1 inhibitor LY2886721 in two clinical trials were tested. This Simoa assay was able to accurately quantify $A \beta_{1-42}$ in all plasma samples tested, demonstrating its capability to support studies of $A \beta$-lowering therapeutics for AD. Similar to previous findings, oral administration of LY2886721 produced rapid and 


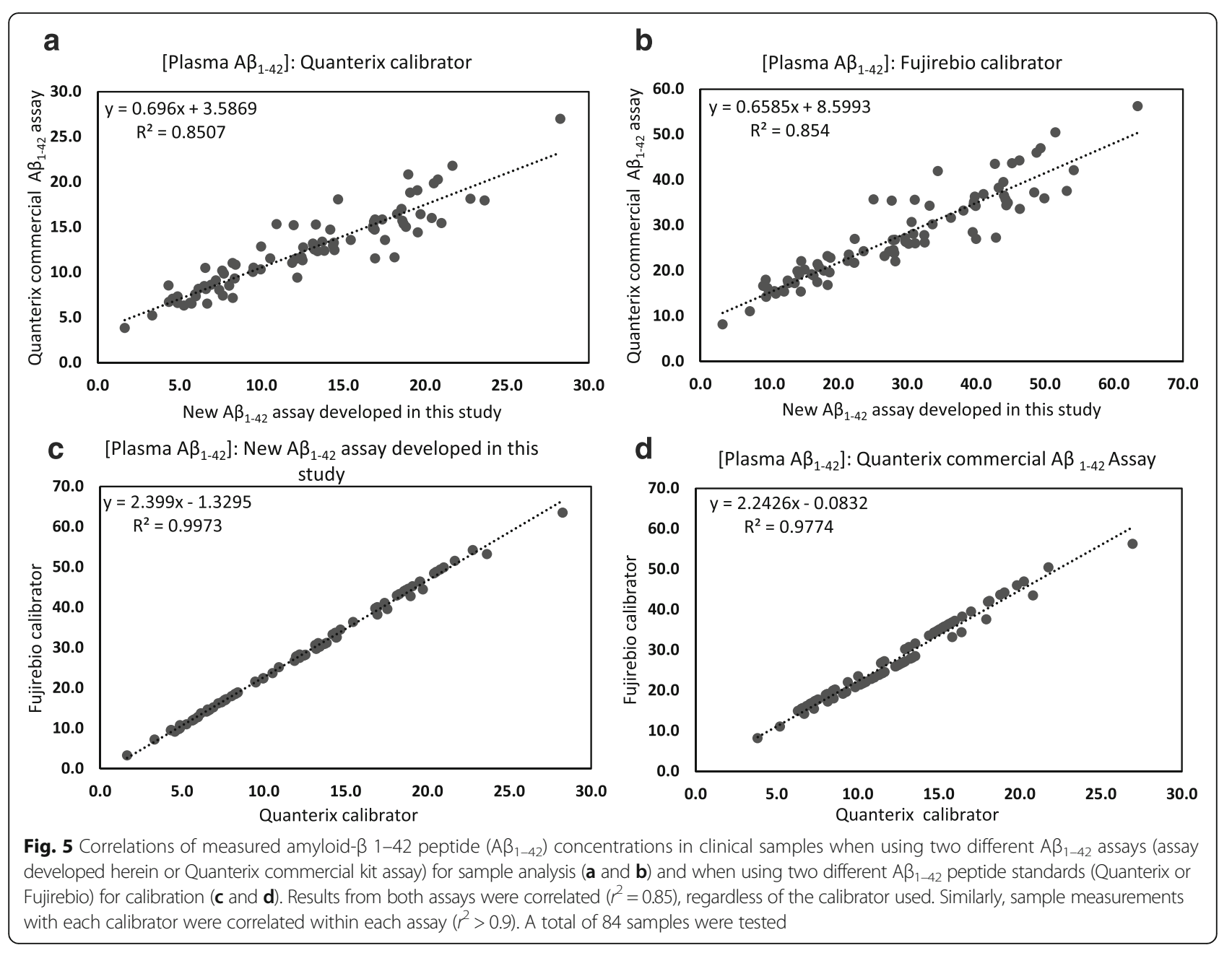

sustained reductions in plasma $A \beta_{1-42}$ levels $[24,32]$. Compared with placebo treatment, reductions of $A \beta_{1-42}$ concentrations were measureable within $1 \mathrm{~h}$, and remained relatively unchanged after $6 \mathrm{~h}$, following single oral doses of LY2886721 in study I4O-MC-BACA. In study $\mathrm{I} 4 \mathrm{O}-\mathrm{MC}-\mathrm{BACB}$, where subjects received multiple oral doses of $5 \mathrm{mg}$ or $15 \mathrm{mg}$ of LY2886721, continuous reductions in $A \beta_{1-42}$ levels were observed over 12 days. However, in the same study, plasma $A \beta_{1-42}$ reached a nadir after day 4 , and further decreases in concentration were relatively minor for those treated with $35 \mathrm{mg}$ of LY2886721. In both studies, a clear, dose-dependent effect of lowering plasma $A \beta_{1-42}$ concentrations was seen (Fig. 4). The assay developed herein was also evaluated in parallel with the Quanterix commercial $A \beta_{1-42}$ assay for utility in clinical sample analysis. Although the Quanterix $A \beta_{1-42}$ assay uses different antibodies from those used to develop the present assay, it exhibits similar analytical sensitivity, and results from the two assays were correlated $\left(r^{2}=0.85\right)$.

\section{Conclusions}

The digital ELISA developed in this study provided sensitive and precise measurement of plasma $A \beta_{1-42}$ in clinical samples treated with the BACE1 inhibitor LY2886721. The improved assay sensitivity enabled $A \beta_{1-42}$ to be reliably quantified even at low picogram-per-milliliter levels. Linearity of measurement with increasing sample dilution was demonstrated, allowing clinical samples with a much larger range of $A \beta_{1-42}$ concentrations to be tested without impacting measurement accuracy. Moreover, the digital ELISA was performed with full automation on the HD-1 Analyzer, with a fast assay turnaround time of $<65$ minutes from sampling to results. With the performance demonstrated in this evaluation study, this Simoa $A \beta_{1-42}$ assay is well-suited for use in studies that involve $\mathrm{AD}$ therapeutic agents aimed at lowering plasma $A \beta$ concentrations.

\section{Abbreviations}

AAA: Amino acid analysis; A $\beta$ : Amyloid- $\beta$; AD: Alzheimer's disease; AEB: Average enzymes per bead; BACE1: $\beta$-Site amyloid precursor protein cleaving enzyme 1; BSA: Bovine serum albumin; CSF: Cerebrospinal fluid; CV\%: Coefficient of 
variation percentage; EDAC: 1-Ethyl-3-(3-dimethylaminopropyl)carbodiimide; EDTA: Ethylenediaminetetraacetic acid; ELISA: Enzyme-linked immunosorbent assay; GS: Y-Secretase; IHP: Immunodepleted human plasma; LLOQ: Lower limit of quantification; LOD: Limit of detection; MES: 2-(N-morpholino)ethanesulfonic acid; 4PL: Four-parameter logistic; QC: Quality control; RE: Relative error;

S/B: Signal-to-background ratio; Simoa: Single molecule array

\section{Acknowledgements}

The authors thank Dr. Philip Barrington, Claire Brittain, and Laura Ramsey for careful review and critical appraisal of the manuscript.

\section{Funding}

All clinical studies referenced were sponsored and funded by Eli Lilly and Company. The present work was performed by Quanterix Corporation, funded and assisted by Eli Lilly and Company.

\section{Availability of data and materials}

All data used to derive the conclusions stated in the article are presented in Tables 1, 2, 3, 4, 5, 6, 7, and 8 .

\section{Authors' contributions}

LS was responsible for the design and execution of the study, data analysis, and drafting and editing the manuscript. DH contributed to editing and critical review of the manuscript. AS prepared all assay reagents and provided critical review of the manuscript. DG assisted with clinical sample analysis and critical review of the manuscript. AJ provided input for the test plan and critical review of the manuscript. DRL planned the assay evaluation and contributed to drafting and editing the manuscript. JAT provided technical and logistical support, clinical sample management, and critical review of the manuscript. MMR provided analysis of $A \beta_{1-42}$ standard contents, prepared immunodepleted plasma, and critically reviewed the manuscript. JLD assisted with data analysis and critical review of the manuscript. RAD provided input into the design of clinical studies, critical review of the test plan, and critical review of the manuscript. All authors read and approved the final manuscript.

\section{Competing interests}

LS, DRL, DH, AS, AJ, DG, JAT, MMR, JLD, RAD

$\mathrm{LS}$ is an employee and minor stock holder of Quanterix Corporation. DH, AS, and DG are holders of stock options and employees of Quanterix Corporation. AJ holds stock options and is a paid consultant of Quanterix Corporation. DRL, JAT, MMR, JLD, and RAD are full-time employees and minor stockholders of Eli Lilly and Company. To the authors' knowledge, there are no nonfinancial conflicts of interest pertinent to the work reported in this article.

\section{Consent for publication}

Not applicable.

\section{Ethics approval and consent to participate}

Samples were provided from previous Lilly-sponsored clinical trials, which were conducted according to the principles of the Declaration of Helsinki and consistent with good clinical practice. A signed informed consent form was obtained from each subject. The ethical review boards involved in the three clinical trials that contributed specimens to the present study are listed below.

Ethical review boards for study I3J-MC-LACE

Site number Ethical review board's name and address

001

California Institutional Review Board, Inc., 110 South Rosemead Boulevard, Suite R2, Pasadena, CA 91107, USA

\section{Ethical review boards for study 140-MC-BACA}

Site number Ethical review board's name and address

$001 \quad$ California Institutional Review Board, Inc., 110 South Rosemead Boulevard, Suite R2, Pasadena, CA 91107, USA
Institutional review boards for study $140-\mathrm{MC}-\mathrm{BACB}$

Site number Ethical review board's

name and address

001

California Institutional
Review Board, Inc., 110
South Rosemead
Boulevard, Suite R2,
Pasadena, CA 91107, USA

Approved study on 4 October 2010.

Retired and closed, and institutional review board (IRB) responsibilities were transferred to Aspire.

Aspire IRB, LLC, 9340 Fuerte Drive, Suite 210, La Mesa, CA 91941, USA

Approved the study on 29 March 2011.

Health Sciences Institutional Review Board, General Hospital, Suite 4700, 1200 North State Street, Los Angeles, CA 90033, USA

Approved the study on 3 October 2010. This IRB was used for the study because its retinal specialist, Dr. Sadda, was contracted separately as a subinvestigator.

\section{Author details}

${ }^{1}$ Quanterix Corporation, Lexington, MA, USA. ${ }^{2}$ Eli Lilly and Company, Windlesham, UK. ${ }^{3}$ Lilly Research Laboratories, Indianapolis, IN, USA.

Received: 18 July 2016 Accepted: 18 November 2016

Published online: 15 December 2016

\section{References}

1. Hardy J, Higgins GA. Alzheimer's disease, the amyloid cascade hypothesis. Science. 1992;286:184-5.

2. Hardy J, Selkoe DJ. The amyloid hypothesis of Alzheimer's disease: progress and problems on the road to therapeutics. Science. 2002;297:353-6.

3. Blennow K de Leon MJ, Zetterberg H. Alzheimer's disease. Lancet. 2006;368:387-403

4. Hardy J. The amyloid hypothesis for Alzheimer's disease: a critical reappraisal. J Neurochem. 2009;110:1129-34.

5. Selkoe DJ. Alzheimer's disease: a central role for amyloid. J Neuropathol Exp Neurol. 1994;53:438-47.

6. Blennow K, Wallin A, Agren H, Spenger C, Siegfried J, Vanmechelen E. Tau protein in cerebrospinal fluid: a biochemical marker for axonal degeneration in Alzheimer disease? Mol Chem Neuropathol. 1995;26:231-45.

7. Younkin SG. The role of A 42 in Alzheimer's disease. J Physiol Paris. 1998;92:289-92.

8. Perrin RJ, Fagan AM, Holtzman DM. Multimodal techniques for diagnosis and prognosis of Alzheimer's disease. Nature. 2009:461:916-22.

9. Sunderland T, Linker G, Mirza N, Putnam KT, Friedman DL, Kimmel LH, et al. Decreased beta-amyloid ${ }_{1-42}$ and increased tau levels in cerebrospinal fluid of patients with Alzheimer disease. JAMA. 2003;289:2094-103.

10. Blennow K, Hampel H. CSF markers for incipient Alzheimer's disease. Lancet Neurol. 2003:2:605-13.

11. Struyfs H, Van Broeck B, Timmers M, Fransen E, Sleegers K, Van Broeckhoven C, et al. Diagnostic accuracy of cerebrospinal fluid amyloid- $\beta$ Isoforms for early and differential dementia diagnosis. J Alzheimers Dis. 2015;45:813-22.

12. Parnetti L, Lanari A, Saggese E, Spaccatini C, Gallai V. Cerebrospinal fluid biochemical markers in early detection and in differential diagnosis of dementia disorders in routine clinical practice. Neurol Sci. 2003:24:199-200.

13. Humpel C. Identifying and validating biomarkers for Alzheimer's disease. Trends Biotechnol. 2011;29:26-32.

14. Borroni B, Premi E, Di Luca M, Padovani A. Combined biomarkers for early Alzheimer disease diagnosis. Curr Med Chem. 2007:14:1171-8.

15. Blennow K. Cerebrospinal fluid protein biomarkers for Alzheimer's disease. NeuroRx. 2004;1:213-25.

16. Mehta PD, Pirttilä T, Mehta SP, Sersen EA, Aisen PS, Wisniewski HM. Plasma and cerebrospinal fluid levels of amyloid $\beta$ proteins $1-40$ and $1-42$ in Alzheimer disease. Arch Neurol. 2000;57:100-5. 
17. Fukumoto $H$, Tennis M, Locascio JJ, Hyman BT, Growdon JH, Irizarry MC. Age but not diagnosis is the main predictor of plasma amyloid $\beta$-protein levels. Arch Neurol. 2003;60:958-64.

18. Toledo JB, Vanderstichele H, Figurski M, Aisen PS, Petersen RC, Weiner MW et al. Factors affecting $A \beta$ plasma levels and their utility as biomarkers in ADNI. Arch Neurol. 2011;122:401-13.

19. Janelidze $S$, Stomrud E, Palmqvist $S$, Zetterberg $H$, van Westen $D$, Jeromin A, et al. Plasma $\beta$-amyloid in Alzheimer's disease and vascular disease. Sci Rep. 2016;6:26801.

20. Galasko D, Golde TE. Biomarkers for Alzheimer's disease in plasma, serum and blood -conceptual and practical problems. Alzheimers Res Ther. 2013;5:10.

21. Blennow K, Hampel $H$, Zetterberg $H$. Biomarkers in amyloid- $\beta$ immunotherapy trials in Alzheimer's disease. Neuropsychopharmacology. 2014;39:189-201.

22. May PC, Dean RA, Lowe SL, Martenyi F, Sheehan SM, Boggs LN, et al. Robust central reduction of amyloid- $\beta$ in human with an orally available, non-peptidic $\beta$-secretase inhibitor. J Neurosci. 2011;31:16507-16.

23. Panza F, Frisardi V, Scolfrizzi V, Imbimbo BP, Logroscino G, Santamato A, et al. Interacting with $\gamma$-secretase for treating Alzheimer's disease: from inhibition to modulation. Curr Med Chem. 2011;18:5430-47.

24. May PC, Willis BA, Lowe SL, Dean RA, Monk SA, Cocke PJ, et al. The potent BACE1 inhibitor LY2886721 elicits robust central A $\beta$ pharmacodynamic responses in mice, dogs, and humans. J Neurosci. 2015:35:1199-210.

25. Miller BB, Mandell JW. Multiplex method for measuring biomarkers in Alzheimer's disease in cerebrospinal fluid. Clin Chem. 2005;51:289-90.

26. Kang JH, Vanderstichele H, Trojanowski JQ, Shaw LM. Simultaneous analysis of cerebrospinal fluid biomarkers using microsphere-based XMAP multiplex technology for early detection of Alzheimer's disease. Methods. 2012;56:484-93.

27. Craig-Schapiro R, Kuhn M, Xiong C, Pickering EH, Liu J, Misko TP, et al. Multiplexed immunoassay panel identifies novel CSF biomarkers for Alzheimer's disease diagnosis and prognosis. PLoS One. 2011;6:e18850

28. Mattsson N, Zegers I, Andreasson U, Bjerke M, Blankenstein MA, Bowser R, et al. Reference measurement procedures for Alzheimer's disease cerebrospinal fluid biomarkers: definitions and approaches with focus on amyloid $\beta 42$ Biomark Med. 2012;6:409-17.

29. Fagan AM, Shaw LM, Xiong C, Vanderstichele H, Mintun MA, Trojanowski JQ, et al. Comparison of analytical platforms for cerebrospinal fluid measures of B-amyloid 1-42, total tau, and p-tau181 for identifying Alzheimer disease amyloid plaque pathology. Arch Neurol. 2011;68(9):1137-44.

30. Kang JH, Korecka M, Toledo JB, Trojanowski JQ, Shaw LM. Clinical utility and analytical challenges in measurement of cerebrospinal fluid amyloid- $\beta$ (1-42) and $\tau$ proteins as Alzheimer disease biomarkers. Clin Chem. 2013;59:903-16.

31. Cullen VC, Fredenburg RA, Evans C, Conliffe PR, Solomon ME. Development and advanced validation of an optimized method for the quantitation of Aß42 in human cerebrospinal fluid. AAPS J. 2012;14:510-8.

32. Lachno DR, Emerson JK, Vanderstichele H, Gonzales C, Martényi F, Konrad RJ, et al. Validation of a multiplexed assay for simultaneous quantification of amyloid- $\beta$ peptide species in human plasma with utility for measurements in studies of Alzheimer's disease therapeutics. J Alzheimers Dis. 2012;32:905-18.

33. Lachno DR, Evert BA, Vanderstichele H, Robertson M, DeMattos RB, Konrad RJ, et al. Validation of assays for measurement of amyloid- $\beta$ peptides in cerebrospinal fluid and plasma specimens from patients with Alzheimer's disease treated with solanezumab. J Alzheimers Dis. 2013;34:897-910.

34. Figurskia MJ, Waligórskaa T, Toledoa J, Vandersticheleb H, Koreckaa M, Leea VMY, et al. Improved protocol for measurement of plasma $\beta$-amyloid in longitudinal evaluation of Alzheimer's Disease Neuroimaging Initiative study patients. Alzheimers Dement. 2012;8:250-60.

35. Lachno DR, Evert BA, Maloney K, Willis BA, Talbot JA, Vandijck M, et al. Validation and clinical utility of ELISA methods for quantification of amyloid- $\beta$ peptides in cerebrospinal fluid specimens from Alzheimer's disease studies. J Alzheimers Dis. 2015:45:527-42.

36. Rissin DM, Kan CW, Campbell TG, Howes SC, Fournier DR, Song L, et al. Single-molecule enzyme-linked immunosorbent assay detects serum proteins at subfemtomolar concentrations. Nat Biotechnol. 2010;28:595-9.

37. Rissin DM, Fournier DR, Piech T, Kan CW, Campbell TG, Song L, et al. Simultaneous detection of single molecules and singulated ensembles of molecules enables immunoassays with broad dynamic range. Anal Chem. 2011:83:2279-85.

38. Zetterbeg H, Mortberg E, Song L, Chang L, Provuncher GK, Patel PP, et al. Hypoxia due to cardiac arrest induces a time-dependent increase in serum amyloid beta levels in humans. PLoS One. 2011;6:e28263.
39. Chang L, Song L, Fournier DR, Kan CW, Patel PP, Ferrell E, et al. Simple diffusion-constrained immunoassay for p24 protein with the sensitivity of nucleic acid amplification for detecting acute HIV infection. J Virol Methods. 2013:88:153-60.

40. Song L, Hanlon DW, Chang L, Provuncher GK, Kan CW, Campbell TG, et al. Single molecule measurements of tumor necrosis factor and interleukin-6 in the plasma of patients with Crohn's disease. J Immunol Methods. 2011;392:177-86.

41. Wilson DH, Rissin DM, Kan CW, Fournier DR, Piech T, Campbell TG, et al. The Simoa HD-1 Analyzer: a novel fully automated digital immunoassay analyzer with single molecule sensitivity and multiplexing. J Lab Autom. 2016;21:533-47.

42. DeMattos RB, O'dell MA, Parsadanian M, Taylor JW, Harmony JA, Bales KR, et al. Clusterin promotes amyloid plaque formation and is critical for neuritic toxicity in a mouse model of Alzheimer's disease. Proc Natl Acad Sci U S A. 2002;99:10843-8.

43. Andreasson $U$, Vanmechelen $E$, Shaw LM, Zetterberg $H$, Vanderstichele $H$. Analytical aspects of molecular Alzheimer's disease biomarkers. Biomark Med. 2012;6:377-89.

44. Okereke O, Xia W, Irizarry MC, Sun X, Qiu W, Fagan AM, et al. Performance characteristics of plasma amyloid- $\beta 40$ and 42 assays. J Alzheimers Dis. 2009;16:277-85

45. van der Burg SH, Kalos M, Gouttefangeas C, Janetzki S, Ottensmeier C, Welters MJP, et al. Harmonization of immune biomarker assays for clinical studies. Sci Transl Med. 2011;3:108ps44.

46. Lista S, Zetterberg H, Dubois B, Blennow K, Hampel H. Cerebrospinal fluid analysis in Alzheimer's disease: technical issues and future developments. J Neurol. 2014;261:1234-43.

\section{Submit your next manuscript to BioMed Central and we will help you at every step:}

- We accept pre-submission inquiries

- Our selector tool helps you to find the most relevant journal

- We provide round the clock customer support

- Convenient online submission

- Thorough peer review

- Inclusion in PubMed and all major indexing services

- Maximum visibility for your research

Submit your manuscript at www.biomedcentral.com/submit
Biomed Central 